\title{
Analisis Beban Kerja dan Disiplin Kerja Terhadap Intensi Turnover Karyawan XYZ
}

\author{
Ahmad Badawi Saluy ${ }^{1}$ dan Novawiguna Kemalasari ${ }^{2}$
}

\begin{abstract}
.
Every organization wants its employees to have a high ability to work discipline, and retain employes. High turnover rate which will cause negative impact to the organization, it is like creating instability and uncertainty of the condition of labor, the organization also lost experienced employees who have been getting a lot of training and ultimately need to retrain new employees. The purpose of this research is to examine and analyze the effect of work load and work discipline on turnover intention. Sampling method using all population. The data is taken directly using a questionnaire with 120 respondents employees at XYZ. The method of analysis used in this research is multiple linear regression, analysis of data using SPSS software. Workload and discipline with the same affect turnover intention by $56.2 \%$ and $43.8 \%$ is explained by other variables. Research shows work load and work discipline togather significantly influence turnover intention. This means that variable turnover intention $(Y)$ can be explained by the two independent variables work load $\left(X_{1}\right)$ and disciplin $\left(X_{2}\right)$. The results of analysis, showed that work load and discipline is a possitive significant effect on turnover intention. Work load variables are variables that most influence on turnover intention,also stated that increased workload contributed toincreasing turnover intention.
\end{abstract}

Keywords: work load, work discipline, turnover intention, Involuntary Turnover, Functional Turnover

\section{PENDAHULUAN}

Sebagai usaha pemerintah untuk memperbaiki kualitas sumber daya manusia melalui pendidikan, kegiatan mendidik mendapatkan dukungan dari berbagai bidang selain itu pemerintah juga menyiapkan pelatihan untuk tenaga pengajar sehingga menyeragamkan penyebaran ilmu pengetahuan keseluruh penjuru nusantara. Sama halnya dalam organisasi, sumber daya manusia merupakan hal terpenting, karena maju ataupun mundurnya suatu organisasi tergantung pada sumber dayanya yang berkualitas sehingga organisasi dapat bersaing tetapi mempertahankan tenaga kerja pendidik di organisasi pendidikan tidaklah mudah.

Organisasi tidak akan luput dari masalah-masalah seperti masalah-masalah antara lain melanggar tata tertib, terlambat, keluar tanpa ijin, dan terlambat dalam menyelesaikan tugas, serta tidak menyelesaikan pengabdiannya. Pada saat yang sama, para karyawan dituntut untuk dapat memberikan pelayanan yang terbaik untuk siswa. Semakin ketatnya peraturan untuk siswa dan tuntutan kinerja para karyawan yang diterapkan pihak manajemen menyebabkan penurunan jumlah karyawan dan siswa yang sudah selesai pengabdian 
tidak berminat untuk menjadi karyawan. Pada akhirnnya, kondisi ini berpengaruh terhadap penerimaan karyawan tetap XYZ.

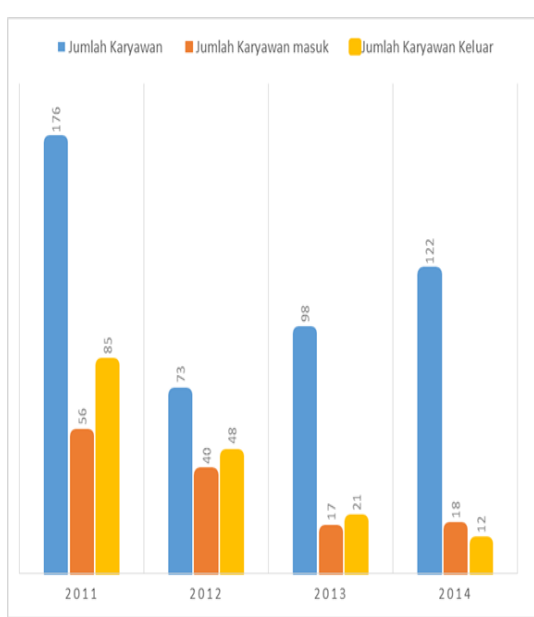

\section{Gambar Data Keluar Masuk karyawan XYZ}

Sumber: Data Bagian Kepegawaian XYZ(2015)

Gambar di atas menunjukkan jumlah karyawan yang keluar dan masuk yang berfluktuasi tetapi jumlah karyawan pada tahun 2011 belum dicapai lagi. Pada tahun 2011 jumlah karyawan mencapai 176 dengan data karyawan keluar berjumlah 85 dan karyawan yang di terima bekerja berjumlah 56 orang. Pada tahun 2012 mengalami penurunan dratis jumlah karyawan hingga menjadi 73 karyawan dengan data karyawan keluar berjumlah 48 dan karyawan yang di terima bekerja berjumlah 40 orang. Mulai mengalami peningkatan jumlah karyawan dari tahun 2013 jumlah karyawan mencapai 98 dengan data karyawan keluar berjumlah 21 orang, karyawan yang di terima bekerja berjumlah 27 orang begitu juga dengan tahun 2014 mencapai 122 orang, dengan data keluar karyawan berjumlah 12 orang dan yang di terima menjadi karyawan berjumlah 18 orang. Berdasarkan informasi yang diperoleh dari observasi dan wawancara diperoleh informasi bahwa dari 20 orang, dari unsur pegawai dan pengabdian, ada sekitar $65 \%$ diantaranya tidak berminat untuk memperpanjang bekerja dan mengabdi di XYZ, Oleh karena itu kondisi ini harus disikapi sebagai fenomena penting yang dapat mengganggu keberlangsungan organisasi.

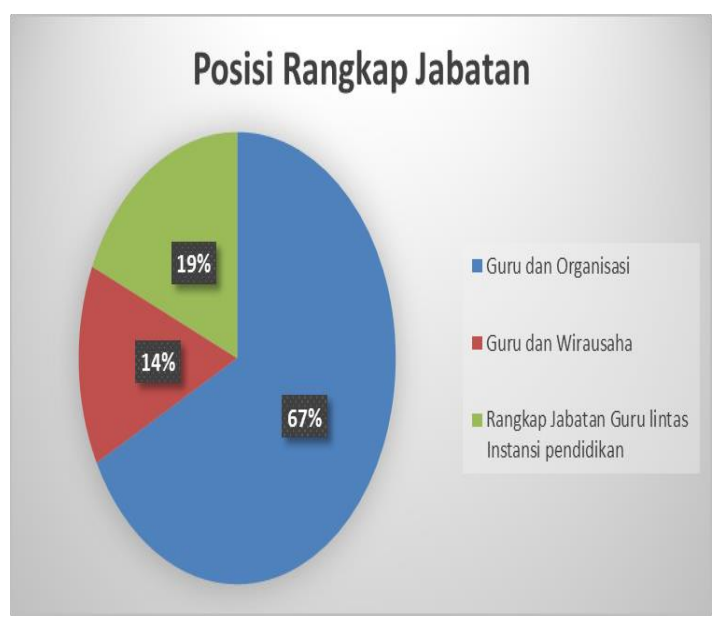

\section{Gambar}

Posisi Rangkap Jabatan XYZ

Sumber: Data Bagian Kepegawaian XYZ (2015)

Gambar di atas menampilkan posisi rangkap jabatan karyawan XYZ, untuk guru yang merangkap pekerjaan bidang organisasi $67 \%$, guru yang merangkap dibidang wirausaha sekitar 14\% dan rangkap jabatan lintas instansi yakni guru jenjang SMP atau SMA merangkap sebagai Dosen sekitar 19\%. 
Karyawan XYZ menjadi satu kesatuan dalam pekerjaan dimana pekerjaan terbagi menjadi tiga bagian yakni organisasi, pendidikan, dan kewirausahaan,

tetapi karyawan harus mampu bekerja dalam dua bidang sekaligus. Karyawan dari bagian kepesantrenan bertugas dan bertanggung jawab di bagian pendidikan ataupun sebaliknya dan bahkan di bagian kewirausahaan. Tugas dan tanggung jawab ganda tersebut menjadi tekanan (stres) yang dapat meningkatkan beban kerja pegawai. Hal ini dapat menyebabkan lambatnya karyawan dalam menyelesaikan tugasnya atau ijin sakit.

Beban kerja yang tinggi juga disebabkan oleh tuntutan untuk sekaligus menjadi orang tua siswa dengan tanggung jawab tambahan melakukan pengawasan penuh pada siswa dimana jika siswa tersebut melanggar sangsi dibebankan pada para karyawan tersebut

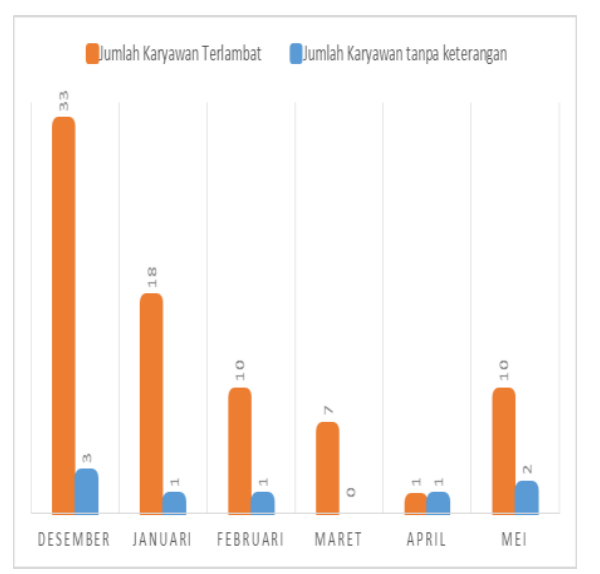

Gambar

Data Kehadiran Karyawan Periode 2014-2015
Sumber: Data Bagian Kepegawaian XYZ (2014-2015)

Dari data gambar di atas menunjukkan tingkat keterlambatan yang tinggi di akhir 2014 dan awal 2015 tiap bulannya dimana jumlah karyawan terlamabat dan karyawan absen tanpa keterangan yang menunjukkan indikasi pelanggaran disiplin terhadap kepatuhan jam kerja, dimana terbanyak pada bulan desember 2014 mencapai hingga 33 orang dan tanpa keterangan berjumlah 3 orang di ikuti bulan januari 2015 berjumlah 18 orang terlambat dan 1 orang tanpa keterangan, kemudian bulan februari 2015 berjumlah 10 orang dan 1 orang tanpa keterangan, dan mulai mengalami penurunan di bulan maret 2015 berjumlah 7 orang terlambat dan tidak ada yang tidak hadir tanpa keterangan, bulan april jumlah yang terlambat 1 orang dan tanpa keterangan 1 orang, tetapi mengalami peningkatan kembali di bulan mei 2015 dengan karyawan terlambat 10 orang dan tanpa keterangan 2 orang. Turnover intentions tidak secara eksplisit memasukkan gagasan ketegangan yang berhubungan dengan pekerjaan dalam model mereka, meskipun fakta bahwa itu adalah terkait dengan perilaku karyawan dari absensinya (Chong et. al., 2015). Pengontrolan absensi karyawan XYZ menggunakan mesin absen sidik jari dan pengontrolan data dilakukan langsung oleh bagian kepegawaian pada komputer yang 
terhubung dengan mesin absen di kantor Badan Administrasi Umum, dan laporannya di emailkan setiap hari kepada Pembina XYZ dan dilakukan tindakan langsung berupa penalti potong gaji bagi yang terlambat di bulan berikutnya.

Peraturan XYZ yang mengatur tentang jam kerja, secara formal yaitu jam pertama diawali jam 07.00 sampai 12.00 kemudian jam ke dua jam 14.00 - 16.00, dan untuk waktu sore jam 18.00 sampai 19.30,enam hari kerja. Panduan waktu kerja, berdasarkan kajian efek kelebihan jam kerja, di Eropa, menyebutkan bahwa untuk menghasilkan pekerjaan yang baik waktu bekerja adalah 11 jam istirahat sehari dengan limit bekerja 48 jam perminggu (Burke et. al., 2009).

Dari latar belakang masalah yang sudah diuraikan diatas maka perlu diteliti lebih lanjut pengaruh beban kerja dan disiplin kerja terhadap intensi turnover karyawan XYZ.

\section{KAJIAN TEORI}

Beban Kerja. Beban kerja adalah sebagai intensitas usaha dibuat oleh para pekerja untuk memenuhi tuntutan dari pekerjaan mereka dalam kondisi fisik yang ditetapkan, dengan mempertimbangkan kondisi mereka sendiri dan berbagai mekanisme bermain dalam pekerjaan mereka (Teiger et. al., 1973; Tort, 1974 dalam Brun et. al., 2011:5-6).
Menurut Kamus Human Resources and Personnel edisi ke tiga management Beban Kerja adalah jumlah pekerjaan yang harus seseorang lakukan (Ivanovic, 2006:278)

Beban kerja guru, lebih didedikasikan untuk mengajar dari pada mengelola dan beban kerja manajer lebih banyak waktunya didedikasikan untuk tugastugas administrasi atau strategi. Oleh karena itu, beban kerja juga berarti suatu kondisi dari pekerjaan dengan uraian tugasnya yang harus diselesaikan pada batas waktu tertentu (Lea et. al., 2012).

Disiplin Kerja. Menurut Ivanovic (2006:79) dalam kamus Human Resource and Personnel Management. Disiplin adalah bentuk pengendalian diri untuk melakukan pekerjaan dan kurangnya disiplin bertanggung jawab terhadap angka kehadiran yang buruk.

Disiplin adalah prosedur yang mengoreksi atau menghukum bawahan karena melanggar peraturan atau prosedur dan merupakan bentuk pengendalian diri pegawai dan pelaksanaan yang teratur dan menunjukkan tingkat kesungguhan tim kerja di dalam sebuah organisasi (Sulistiyani, 2009:290). Makna lain dari kata yang sama adalah seseorang yang mengikuti pemimpinnya. Menurut Devis dalam Mangkunegara (2013:129) mengemukakan bahwa "Dicipline is management action to enforce organization standars" yang dapat diartikan disiplin kerja sebagai pelaksana 
manajemen untuk memperteguh pedomanpedoman organisasi.

Disiplin kerja (Rivai, 2008: 444 dalam Wisantyo, 2015) adalah suatu alat yang digunakan para manajer untuk berkomunikasi dengan karyawan agar mereka bersedia untuk mengubah suatu perilaku serta suatu upaya untuk meningkatkan kesadaran dan kesediaan seseorang mentaati semua peraturan perusahaan dan norma-norma sosial yang berlaku. Seorang karyawan yang dikatakan memiliki disiplin kerja yang tinggi jika yang bersangkutan konsekuen, konsisten, taat asas, bertanggung jawab atas tugas yang diamanatkan kepadanya. Disiplin kerja dapat meliputi: Teladan dan panutan dari pemimpin; Kesesuaian dari balas jasa dan kesamaan perilaku; Disiplin oleh semua orang dan pengawasan dari pengawas; Sanksi jika disiplin tidak ditepati; Konsistensi penegakan disiplin; Ketertiban dalam lingkungan kerja (Hasibuan, 2007: 195-198).

Intensi Turnover Turnover adalah tingkat keluar masuk karyawan terjadi ketika karyawan meninggalkan organisasi dan harus digantikan. Intensi turnover mencerminkan keinginan individu untuk meninggalkan organisasi dan mencari alternatif pekerjaan di tempat lain (Mathis dan Jackson, 2010: 159). Mello (2011:62) berpendapat bahwa memperkirakan suplai tenaga kerja untuk memenuhi jumlah karyawan bukan ukuran yang statik tetapi lebih kepada dinamis. Dalam organisasi yang sedang maupun besar, pergantian posisi tenaga kerja dan tingkat kerja konstan atau meninggalkan organisasi. Karena itu setiap upaya untuk menilai pasokan karyawan perlu untuk menilai mobilitas dalam organisasi serta turnover.

Baik voluntary turnover maupun involuntary turnover dapat menimbulkan biaya bagi organisasi (Mathis dan Jackson, 2010: 160). Biaya turnover misalnya biaya untuk pelatihan karyawan baru serta biaya yang diperlukan bagi karyawan baru untuk mendapatkan kemampuan dalam pekerjaannya sehingga dapat disosialisasikan dan diintegrasikan ke dalam organisasi.

Bagaimanapun costs of turnover yang dikeluarkan, telah memunculkan analisis mengenai sebab-sebab yang menimbulkannya (Sulistiyani, 2009:253).

Berdasarkan penjelasan di atas, intensi turnover dapat disimpulkan sebagai bentuk keinginann seseorang yang berada di dalam organisasi atau perusahaan untuk keluar baik dari dirinya maupun pengaruh dari luar, dan berpengaruh bagi organisasi atau perusahaan dari segi biaya. Intensi turnover ini meliputi antara lain: Involuntary turnover; Voluntary turnover; Functional turnover; Dysfunctional turnover; Controllable turnover dan Uncontrollable turnover (Mathis dan Jackson (2010:160-161)). 


\section{Pengaruh Disiplin Kerja terhadap Intensi}

Turnover. Disiplin kerja adalah suatu keadaan dimana seorang atau sekelompok orang dalam organisasi yang mematuhi dan menjalankan peraturan-peraturan perusahaan baik tertulis maupun tidak tertulis dengan ditandai kesadaran akan tercapainya suatu keinginan dan kenyataan yang diharapkan agar pegawai memiliki sikap disiplin yang tinggi dalam bekerja sehingga produktivitasnya meningkat. Kesadaran dan kesediaan seseorang mentaati semua peraturan perusahaan dan norma-norma sosial yang berlaku merupakan bentuk penerimaan akan perusahaannya. Dalam menjalankan kegiatan kerja, pegawai yang datang dan pulang tepat waktunya, mengerjakan semua pekerjaannya dengan baik, mematuhi semua peraturan perusahaan dan norma-norma sosial yang berlaku mencerminkan kenyamanan pegawai yang dapat mencegah keinginan meninggalkan perusahaan. Hal ini tidak didukung oleh hasil penelitian yang dilakukan oleh (Nurmalitasari Indah et. al., 2015) yang menyatakan bahwa disiplin kerja berpengaruh terhadap intensi turnover tetapi tidak signifikan. Berdasarkan matrik antar dimensi, hal ini dapat dikarenakan dimensi yang digunakan banyak yang hubungannya lemah. dan berbeda dengan hasil penelitian Lavenant (2010) yang menyatakan bahwa mendidik supervisor tentang aturan-aturan akan memberi mereka keseimbangan yang tepat antra otoritas dan penerimaan yang hasilnya turnover rendah dan produktivitas yang tinggi bagi organisasi. Sehingga dapat ditarik hipotesa $\left(\mathrm{H}_{2}\right)$ disiplin kerja berpengaruh terhadap intensi turnover.

Pengaruh Beban Kerja, Disiplin Kerja terhadap Intensi Turnover. Waktu kerja mempengaruhi beban kerja seorang karyawan. Waktu kerja ini dilihat dari kesesuaian dengan standar waktu kerja yang dikeluarkan Departemen Kesehatan (Depkes) RI, yaitu waktu normal per hari adalah delapan jam lima hari kerja. Dan jika seseorang bekerja melebihi waktu tersebut maka dapat dikatakan mengalami beban kerja berlebih.

Selain itu manajer harus melihat berbagai pengetahuan sebagai cara untuk mengubah karyawan menjadi pekerja yang lebih baik. Namun, pengakuan yang tulus dalam bentuk token penghargaan, seperti surat prestasi, upacara penghargaan, atau hadiah kecil, memberikan karyawan rasa yang kontribusi mereka peduli dan diperhatikan oleh supervisor dan manajemen atas. Namun demikian, seperti beban kerja menurun sebanding dengan tanggung jawab sosial dan berbagai pengetahuan karena baik untuk organisasi (Chiem 2001 dalam Michael Stankosky, 2005:83). Sehingga dapat ditarik hipotesa $\left(\mathrm{H}_{3}\right)$ beban kerja dan disiplin kerja berpengaruh terhadap intensi turnover. 


\section{Pengaruh Beban Kerja terhadap Intensi}

Turnover. Beban kerja berpengaruh terhadap turnover, hal ini tidak hanya individu yang menanggung konsekuensi dari beban kerja, tetapi organisasi juga mereka harus menyerap biaya ketidakhadiran, bonus dan turnover karyawan yang terkait dengan tuntutan dan kondisi kerja yang sulit. Dalam jangka panjang organisasi beresiko melihat penurunan kuantitas dan kualitas produk mereka (Beech-Hawley, et. al., 2004; Rochefort, 2000 ) dan jasa (Du Tertre, 2006; Rousseau dan Sarazin, 2006) karena inisiatif peredam beban kerja karyawan meningkat dan kreatifitas (Pierre et. al., 2011:5).

Beban kerja berdasarkan jumlah dari pekerjaan yang dialokasikan kepada karyawan. Dari berbagai penelitian mendukung hubungan positif antara beban kerja, stres dan turnover. (Glaser et. al., dalam Qureshi et. al., 2013) menemukan bahwa hubungan signifikan antara beban kerja dan stres serta stres dan turnover penelitian ini mengasumsikan bahwa stres akan bermain sebagai abitrator role antara beban kerja dan turnover intentions. Sehingga dapat ditarik hipotesa $\left(\mathrm{H}_{1}\right)$ beban kerja berpengaruh terhadap intensi turnover.

Hipotesis penelitian ini dapat diajukan sebagai berikut:

$\mathrm{H}_{1} \quad$ : Beban kerja berpengaruh terhadap intensi turnover karyawan XYZ
$\mathrm{H}_{2} \quad$ : Disiplin kerja berpengaruh terhadap intensi turnover karyawan XYZ

$\mathrm{H}_{3} \quad$ : Beban kerja dan disiplin kerja secara bersama-sama berpengaruh terhadap intensi turnover karyawan XYZ.

\section{METODE}

Desain penelitian yang digunakan dalam penelitian ini adalah desain penelitian kausal dan deskriptif. Desain penelitian kausal digunakan untuk mengukur hubungan antara beban kerja dan disiplin kerja terhadap intensi turnover, serta untuk menganalisa bagaimana variabel beban kerja dan disiplin kerja mempengaruhi variabel intensi turnover pegawai. Sedangkan, desain penelitian deskriptif digunakan untuk memaparkan atau menjelaskan variabel-variabel yang diteliti dan melihat hubungan serta ketergantungan variabel pada sub-sub variabelnya.

Di dalam penelitian ini yang merupakan variabel independen yaitu variabel beban kerja $\left(\mathrm{X}_{1}\right)$, dan variabel disiplin kerja $\left(\mathrm{X}_{2}\right)$. Selain itu terdapat variabel dependen yaitu variabel intensi turnover (Y). Definisi operasional dari variabel-variabel tersebut sebagai berikut: Beban kerja dapat berasal dari seberapa besar aktivitas mental; Jumlah aktivitas fisik; Jumlah tekanan karena waktu; Tingkat keberhasilan dalam pekerjaan; Tingkat frustasi yang dialami; Kesulitan yang dihadapi; dan pengetahuan tentang tujuan pekerjaan. Disiplin kerja dapat meliputi: 
Teladan dan panutan dari pemimpin; Kesesuaian dari balas jasa dan kesamaan perilaku; Disiplin oleh semua orang dan pengawasan dari pengawas; Sanksi jika disiplin tidak ditepati; Konsistensi penegakan disiplin; Ketertiban dalam lingkungan kerja. Intensi turnover ini meliputi antara lain: Involuntary turnover; Voluntary turnover; Functional turnover; Dysfunctional turnover; Controllable turnover dan Uncontrollable turnover.

Unit analilis penelitian ini adalah individu yakni karyawan. Berdasarkan data tahun 2014-2015, populasi dalam penelitian ini berjumlah 120 (seratus dua puluh) orang, dimana analisa populasi penelitian ini adalah seluruh karyawan XYZ. Teknik pengumpulan data yang digunakan di dalam penelitian ini melalui penyebaran kuesioner dan telaah dokumen yang terkait dengan variabel yang digunakan di dalam peneitian ini. Kuesioner penelitian ini menggunakan jenis kuesioner tertutup dimana kuesioner tersebut sudah disediakan jawabannya sehingga responden tinggal memilih alternatif jawaban yang ada. Kuesioner yang digunakan di dalam penelitian ini menggunakan skala pengukuran yang berdasarkan skala Likert 1-4. Pengujian validitas instrumen di dalam penelitian ini dilakukan dengan metode korelasi Product Moment Pearson. Metode pengujian reliabilitas adalah dengan menggunakan metode Cronbach Alpha, yaitu dengan membagi alat ukur sebanyak jumlah item. Reliabilitas reliabel jika > 0.70 (Umar, 2013:56), pada nilai signifikansi 0.05 terhadap 30 responden. Peneliian ini menggunakan metode analisis Uji regresi linier berganda:

$$
\mathrm{Y}=\mathrm{a}+\mathrm{b}_{1} \mathrm{X}_{1}+\mathrm{b}_{2} \mathrm{X}_{2}
$$

karena pada penelitian ini terdapat lebih dari satu variabel independen (bebas). Model regresi yang diteliti harus memenuhi asumsi klasik regresi linier ganda. Oleh karena itu variabel yang akan diteliti perlu diuji untuk mengetahui hal-hal berikut (Umar, 2013:77):

1. Apakah data berdistribusi normal atau tidak?

2. Apakah data memiliki sifat multikolinieritas atau tidak?

3. Apakah data memiliki sifat homoskedastisitas atau tidak?

1). Uji Normalitas: Uji normalitas dapat dilakukan dengan melihat Normal P-P Plot of Regression Stand. Jika data menyebar di sekitar garis diagonal dan mengikuti arah diagonalnya, model regresi memenuhi asumsi normalitas.

2). Uji Multikolinieritas: Sujarweni (2015:185) menjelaskan bahwa nilai VIFantara 1-10 maka tidak terjadi multikolinieritas. 
3). Uji Heteroskedastisitas: menurut Sujarweni (2015:181) model regresi linier berganda dapat disebut sebagai model yang baik jika model tersebut memenuhi asumsi normalitas dan bebas dari asumsi klasik statistik baik itu multikolinieritasdan heteroskedastisitas. Heteroskedastisitas muncul apabila kesalahan atau residual dari model yang diamati tidak memiliki varians yang konstan dari satu observasi ke observasi lainnya (Kuncoro, 2011:118). Cara menentukan heteroskedastisitas dapat dilakukan dengan berbagai cara diantaranya: Residual Plot, Metode Grafik, Uji Park, Uji Glejser, dan kelajiman (Umar, 2013:82).

\section{HASIL DAN PEMBAHASAN}

Hasil uji validitas dan reliabilitas instrumen disajikan pada Tabel 1. Dapat dilihat bahwa seluruh item indikator valid dan reliabel:

Tabel

Uji Validitas dan Reliabilitas

\begin{tabular}{lllll}
\hline $\mathrm{N}$ & Variabel & Validitas & $\begin{array}{l}\text { Reliabilit } \\
\mathrm{a}\end{array}$ \\
\hline 1 & Beban Kerja & $\begin{array}{l}10 \\
\text { valid }\end{array}$ & Item & .873 \\
& $\begin{array}{l}\text { Disiplin } \\
\text { Kerja }\end{array}$ & $\begin{array}{l}20 \\
\text { valid }\end{array}$ & item & .767 \\
3 & $\begin{array}{l}\text { Intensi } \\
\text { Turnover }\end{array}$ & $\begin{array}{l}\text { 20 } \\
\text { valid }\end{array}$ & item & .865 \\
& & & \\
\hline
\end{tabular}

Sumber: Hasil Olahan dengan SPSS (2016)

Hasil pengujian asumsi klasik menunjukkan bahwa distribusi data bersifat normal. Tidak terjadi multikoliniearitas maupun heteroskedastisitas. Pengujian persamaan regresi linier dapat dirangkum sebagai berikut:

Tabel

Analisis Regresi Linier Berganda

\begin{tabular}{lcrrr}
\hline Variabel & $\begin{array}{c}\text { Koefisien } \\
\text { Regresi }\end{array}$ & $\begin{array}{c}\text { Bet } \\
\text { a }\end{array}$ & T & Sig \\
\hline Konstan & 1,231 & & & \\
ta & & & & \\
$\mathrm{X}_{1}$ (beba & 0,565 & 0, & 5,8 & 0,0 \\
$\mathrm{n}$ kerja) & & 44 & 55 & 00 \\
& & 8 & & \\
$\mathrm{X}_{2}$ (disip & 0,475 & 0, & 5,1 & 0,0 \\
lin & & 39 & 06 & 00 \\
kerja) & & 0 & & \\
\hline $\mathrm{F}_{\text {hitung }}=75,045$ & & & \\
$\mathrm{R}^{2}=0,562$ & & & \\
\hline
\end{tabular}

a. Predictors: (Constant), Disiplin Kerja

$\left(\mathrm{X}_{2}\right)$, Beban $\operatorname{Kerja}\left(\mathrm{X}_{1}\right)$

b. Dependent Variable: Intensi

Turnover

Sumber: Hasil Olahan dengan SPSS (2016)

Nilai $t_{\text {hitung }}$ untuk variabel beban kerja adalah 5.855 sedangkan nilai $\mathrm{t}$ tabel 1.980 sehingga $t_{\text {hitung }}>t_{\text {tabel. }}$. Sementara itu nilai signifikansi sebesar 0.000 yang berarti < nilai $\alpha(0.05)$. Dengan demikian disimpulkan bahwa variabel beban kerja berpengaruh terhadap variabel intensi turnover karyawan XYZ. Sesuai dengan penelitian yang dilakukan Qureshi (2013) dan didukung oleh Makela (2014) yang menyimpulkan beban kerja berpengaruh terhadap intensif turnover karyawan. Nilai $t_{\text {hitung }}$ untuk variabel disiplin 
kerja adalah 5.106 bernilai positif sedangkan nilai $\mathrm{t}$ tabel 1.980 sehingga $\mathrm{t}_{\text {hitung }}>\mathrm{t}_{\text {tabel }}$. Sementara itu nilai signifikansi sebesar 0.000 yang berarti $<$ nilai $\alpha(0.05)$. Dengan demikian disimpulkan bahwa disiplin kerja berpengaruh terhadap intensi turnover karyawan XYZ. Sesuai dengan hasil penelitian dari Gormley (2011), Kademi et al., (2012) dan Bukchin et., al., (2013) variabel disiplin kerja berpengaruh signifikan terhadap peningkatan variabel intensi turnover. Berbeda dengan hasil penelitian Wisantyo (2015) yang menyimpulkan disiplin kerja berpengaruh positif tetapi tidak signifikan terhadap intensi turnover.

Dari kedua variabel independen diatas, variabel beban kerja paling berpengaruh terhadap variabel intensi turnover karena nilai beta variabel beban kerja paling besar diantara nilai beta variabel yang lain, yaitu 0.448, diikuti variabel disiplin kerja sebesar 0.390. Pada penelitian ini dilakukan uji Anova yang membandingkan antara mean square dari regression dan mean square dari residual sehingga didapat hasil yang dinamakan $F_{\text {hitung. Apabila }} F_{\text {hitung }}>F_{\text {tabel }}$ dan apabila tingkat signifikansi lebih kecil dari $\alpha(0.05)$, maka disimpulkan bahwa variabel independen secara bersama-sama berpengaruh terhadap variabel dependen. Nilai $F_{\text {hitung }}=75.045$, sedangkan $F_{\text {tabel }}$ adalah
3.07 dengan ketentuan derajat kebebasan atau $\mathrm{df}_{1}$ (pembilang) $=\mathrm{k}-1 ; 3-1=2$ dan $\mathrm{df}_{2}$ (penyebut) $=\mathrm{n}-\mathrm{k} ; \quad 120-3=117$, sehingga diperoleh nilai $F_{\text {hitung }}>F_{\text {tabel }}$ maka $H_{o}$ ditolak. Nilai signifikansi (sig) pada tabel diatas adalah 0.000 , dimana nilai tersebut berarti nilai signifikansi $(\mathrm{sig})<\alpha(0.05)$ maka $\mathrm{H}_{0}$ ditolak.

Hasil uji $F$ menunjukkan bahwa $F_{\text {hitung }}(75.045)>F_{\text {tabel }}(3.07)$ dan nilai signifikansi $(0.000)<\alpha(0.05)$, sehingga disimpulkan bahwa $\mathrm{X}_{1}$ (beban kerja) dan $\mathrm{X}_{2}$ (disiplin kerja) secara bersama-sama berpengaruh terhadap $\mathrm{Y}$ (intensi turnover). Beban kerja dan penekanan disiplin yang diterima karyawan XYZ mendorong karyawan untuk lebih memilih untuk tidak menghabiskan karir kerja di XYZ, sehingga ini meningkatkan intensi turnover karyawan yang dihadapi oleh bagian kepegawaian.

Koefisien determinasi $\left(r^{2}\right)$ adalah sebesar 0.562. Nilai ini menunjukkan bahwa beban kerja $\left(\mathrm{X}_{1}\right)$ dan disiplin kerja $\left(\mathrm{X}_{2}\right)$ secara bersama-sama mempengaruhi variabel intensi turnover (Y) sebesar $56.2 \%$, sedangkan $43.8 \%$ dijelaskan oleh variabel bebas (independen) lainnya yang tidak diteliti dalam penelitian ini diantaranya gaya kepemimpinan, budaya organisasi, kompensasi, stres kerja berdasarkan penelitian sebelumnya yang mempengaruhi intensi turnover. 
Persamaan estimasi model regresi linier berganda untuk intensi turnover karyawan XYZ adalah: Intensi Turnover $=1.231+$ $0.565 * X_{1}+0.475 * X_{2}$

Koefisien regresi konstanta (a) sebesar 1.231 menunjukkan bahwa dengan tidak adanya nilai koefisien variabel beban kerja dan disiplin kerja maka nilai variabel intensi turnover XYZ sebesar 1.231, dan angka tersebut memiliki makna bahwa intensi turnover di XYZ cukup tinggi. Keinginan meninggalkan XYZ tidak hanya didasari karena tekanan yang dirasakan ataupun kesediaan seorang karyawan mentaati semua peraturan organisasi. Kepastian keberlanjutan suatu organisasi perlu diperhatikan karena hal tersebut berkaitan dengan rasa nyaman karyawan dalam bekerja. Untuk itu diperlukan penggalian informasi yang lebih dalam agar ditemukan faktor-faktor apa saja yang harus diperbaiki demi menurunkan intensi turnover karyawan XYZ, terutama variabel beban kerja dan variabel disiplin kerja.

Koefisien regresi variabel beban kerja $\left(b_{1}\right)=0.565$ dengan nilai signifikansi 0.000 hal tersebut mengandung pengertian bahwa apabila variabel beban kerja meningkat satu satuan, maka variabel intensi turnover naik 0.565 , dimana 0.565 berbeda nyata dengan 0 , tidak sama dengan 0 . Kenaikan tersebut menunjukkan bahwa variabel beban kerja berpengaruh signifikan terhadap variabel intensi turnover karyawan XYZ.

Koefisien regresi variabel disiplin kerja $\left(b_{2}\right)=0.475$ dengan nilai signifikansi 0.000 hal tersebut mengandung pengertian bahwa apabila variabel disiplin kerja meningkat satu satuan, maka variabel intensi turnover naik 0.475 , dimana 0,475 berbeda nyata dengan 0 , tidak sama dengan 0 kenaikan tersebut menunjukkan bahwa variabel disiplin kerja berpengaruh signifikan terhadap variabel intensi turnover karyawan XYZ.

Tabel

Perbandingan Penelitian Terdahulu

\begin{tabular}{|c|c|c|c|c|}
\hline $\begin{array}{c}\text { Varia } \\
\text { bel }\end{array}$ & $\begin{array}{c}\text { Wisan } \\
\text { tyo } \\
(2015 \\
)\end{array}$ & $\begin{array}{l}\text { Nurhas } \\
\text { mandia } \\
r \\
\text { Nadini, } \\
\text { et., al. } \\
2013\end{array}$ & $\begin{array}{c}\text { Burke } \\
\text { et } \\
\text { al.,(20 } \\
\text { 10) }\end{array}$ & $\begin{array}{c}\text { Guglie } \\
\text { mi et } \\
\text { al.,(20 } \\
12)\end{array}$ \\
\hline X1 & $\sqrt{ }$ & $\sqrt{ }$ & $\sqrt{ }$ & $\sqrt{ }$ \\
\hline X2 & $x$ & & $\sqrt{ }$ & $\sqrt{ }$ \\
\hline $\mathbf{Y}$ & $\sqrt{ }$ & $\sqrt{ }$ & $\sqrt{ }$ & $\sqrt{ }$ \\
\hline
\end{tabular}

$\sqrt{ }$ : Berpengaruh dan signifikan

$x$ : Berpengaruh dan tidak sifgnifikan Sumber: Hasil Olahan Penulis

Analisis Dimensi: Untuk melakukan analisis dimensi diperlukan matrik korelasi dimana antar variabel independen dengan variabel dependen. Hal tersebut dilakukan untuk meneliti kuat hubungan dimensi antar variabel sehingga dapat ditemukan dimensi yang dominan mempengaruhi variabel yang bersangkutan. 
Tabel

Matriks Korelasi Dimensi Antar Variabel

\begin{tabular}{|c|c|c|c|c|c|c|c|}
\hline \multicolumn{8}{|l|}{ Variabel } \\
\hline & Dimensi & $\begin{array}{c}\text { (Y1) } \\
\text { Involuntary } \\
\text { Turnover }\end{array}$ & $\begin{array}{c}\text { (Y2) } \\
\text { Voluntary } \\
\text { Turnover }\end{array}$ & $\begin{array}{c}\mathrm{Y} 3) \\
\text { Functional } \\
\text { Turnover }\end{array}$ & $\begin{array}{c}\text { (Y4) } \\
\text { Dysfunctional } \\
\text { Turnover }\end{array}$ & $\begin{array}{c}\text { (Y5) } \\
\text { Uncontrollabl } \\
\text { e Turnover }\end{array}$ & $\begin{array}{c}\text { (Y6) } \\
\text { Controllable } \\
\text { Tunover }\end{array}$ \\
\hline Beban & (X1,1) Usaha Mental & ,321 & ,226 & ,303 & ,345 & 301 & 414 \\
\hline \multirow{2}{*}{ Kerja } & (X1,2)Usaha Fisik & ,303 & ,223 & ,324 & .101 & ,231 & ,324 \\
\hline & $(\mathrm{X} 1,3)$ Usaha Sementara & ,483 & ,385 & ,426 & 185 & ,311 & ,285 \\
\hline \multirow[t]{3}{*}{ (X1) } & (X1,4)Performansi & 186 & ,235 & 297 & ,243 & ,221 & ,384 \\
\hline & (X1,5)Tingkat Frutasi & ,324 & 249 & ,375 & ,250 & ,340 & ,388 \\
\hline & $(\mathrm{X} 1,6)$ Kesulitan Tugas & ,391 & ,285 & ,337 & 369 & ,390 & ,401 \\
\hline Disiplin & $(X 2,1)$ Tujuan dan Kemampuan & ,420 & ,422 & ,495 & ,215 & .158 & .020 \\
\hline \multirow{2}{*}{ Kerja } & $(\mathrm{X} 2,2)$ Keteladanan pimpinan & ,429 & ,362 & ,469 & ,258 & ,254 & 231 \\
\hline & $(\mathrm{X} 2,3)$ Balas Jasa & ,353 & ,332 & ,431 & .107 & 195 & .004 \\
\hline \multirow[t]{5}{*}{ (X2) } & $(X 2,4)$ Keadilan & ,480 & ,306 & ,428 & ,235 & ,228 & ,261 \\
\hline & $(X 2,5)$ Waskat & ,376 & ,354 & ,433 & ,289 & ,222 & .135 \\
\hline & $(X 2,6)$ Sanksi & ,245 & .123 & ,296 & ,236 & ,359 & ,329 \\
\hline & $(X 2,7)$ Ketegasan & ,226 & 231 & ,302 & 369 & ,392 & ,392 \\
\hline & (X2,8)Hubungan Kemanusiaan & ,275 & .179 & 197 & ,381 & ,343 & ,448 \\
\hline
\end{tabular}

Sumber : Hasil Olahan dengan SPSS (2016)

Korelasi sedang dan positif sebesar 0.483 antara dimensi usaha sementara dengan dimensi involuntary turnover, dimana karyawan tidak berpikir untuk menghabiskan karir di XYZ, dan berpikir untuk mencari pekerjaan di perusahaan lain yang dikarenakan tidak kuat dengan standar dan peraturan kerja. XYZ harus meningkatkan kebijakan organisasi, memperbaiki peraturan kerja dan standar kerja yang belum terpenuhi oleh karyawan XYZ serta mengurangi jumlah tekanan yang berkaitan dengan waktu yang dirasakan selama elemen pekerjaan berlangsung. 
Korelasi sedang dan positif sebesar 0.495 antara dimensi tujuan dan kemampuan dengan dimensi functionall tunover, menunjukkan bahwa karyawan XYZ lebih tertarik untuk bekerja di pekerjaan yang lebih santai dan memiliki waktu fleksibel. Karyawan merupakan orang yang berada pada pekerjaan sesuai dengan kemampuan dan memahami tujuan dari XYZ, dimana karyawan tersebut yang memiliki kinerja rendah atau karyawan yang mengganggu keluar, serta tujuan yang dibebankan kepada karyawan dari organisasi harus jelas dan ditetapkan secara ideal dan menantang bagi kemampuan karyawan, pekerjaan yang dibebankan kepada seseorang karyawan harus sesuai dengan kemampuan karyawan bersangkutan. Tetapi jika pekerjaan itu di luar kemampuannya atau jauh di bawah kemampuannya maka kesungguhan dan kedisiplinan karyawan akan rendah. Di sini letak pentingnya asas the right man in the right place, the right man on the right job (Mangkunegara, 2013:67).

\section{PENUTUP}

Beban kerja berpengaruh terhadap intensi turnover karyawan XYZ secara positif dan signifikan. Dimensi pada variabel beban kerja yang paling kuat hubungannya adalah dimensi usaha sementara terhadap dimensi involuntary turnover dimana karyawan tidak berpikir untuk menghabiskan karir di XYZ, dan berpikir untuk mencari pekerjaan di tempat lain. Perubahan beban kerja mempunyai pengaruh searah perubahan intensi turnover.

Disiplin kerja berpengaruh terhadap intensi turnover karyawan XYZ secara positif dan signifikan. Dimensi pada variabel disiplin kerja yang paling kuat hubungannya adalah dimensi tujuan dan kemampuan terhadap dimensi functionall turnover menunjukkan bahwa karyawan XYZ lebih tertarik untuk bekerja di pekerjaan yang lebih santai dan memiliki waktu fleksibel. Apabila terjadi kenaikan disiplin kerja maka intensi turnover akan terjadi kenaikan.

Beban kerja dan disiplin kerja berpengaruh secara bersama-sama berpengaruh positif dan signifikan terhadap intensif turnover karyawan $\mathrm{XYZ}$, artinya beban kerja dan disiplin kerja harus lebih diperhatikan oleh pihak manajemen agar bisa mengantisipasi timbulnya turnover karyawan XYZ.

Perlu perhatian dari pihak manajemen XYZ untuk menentukan setandar dan jadwal kerja yang teratur dan terjadwal sehingga pemerataan pekerjaan dapat lebih merata sehingga mengurangi jumlah tekanan yang berkaitan dengan waktu. Pihak manajemen XYZ perlu menambah tenaga kerja di bidang kewirausahaan dan kepesantrenan sehingga karyawan dibidang pendidikan dapat fokus di bidang pendidikan 
dan tidak terjadi kelebihan beban pekerjaan dikarenakan usaha sementara yang timbul. Beban kerja melalui dimensi-dimensinya seberapa besar aktivitas mental, jumlah aktivitas fisik, jumlah tekanan karena waktu, tingkat keberhasilan dalam pekerjaan, tingkat frustasi yang dialami, kesulitan yang dihadapi, dan pengetahuan tentang tujuan pekerjaan, yang semuanya harus diperhatikan guna menekan intensi turnover karyawan.

Dalam penelitian ini, variabel disiplin kerja berpengaruh terhadap intensi turnover pegawai XYZ secara signifikan dan positif. Pemberian sanksi yang sesuai prosedur dan jelas perlu dipertahankan. serta tujuan yang dibebankan kepada karyawan dari organisasi harus jelas dan ditetapkan secara ideal dan menantang bagi kemampuan karyawan, hal ini akan memberikan kejelasan pegawai XYZ untuk bekerja sesuai aturan dan aman dalam menjalankan tugasnya.

Perlu diperhatikan kedua-duanya antara beban kerja dan disiplin kerja secara bersama-sama berdasarkan hipotesis penelitian antara beban kerja dan disiplin kerja tersebut berpengaruh terhadap intensi turnover ini artinya tidak hanya beban kerja saja yang berpengaruh terhadap intensi turnover tetapi disiplin kerja juga berpengaruh. Dengan terpenuhi kebutuhan pegawai dan bersikap adil sehingga mengurangi intensi turnover dengan sendirinya karyawan XYZ akan bekerja dengan lebih baik, profesional, dan bertanggung jawab.

Penelitian dimasa depan pada intensi turnover dapat lebih dikembangkan pada variabel-variabel lain yang tidak diteliti dalam penelitian ini seperti variabel kepuasan kerja, variabel gaji, budaya organisasi dan gaya kepemimpinan dan masih banyak lagi yang dapat mempengaruhi intensi turnover karyawan. Secara akademis bisa dipakai untuk bahan pengembangan teori dari manajemen sumber daya manusia dan bisa menjadi bahan rujukan. Beban kerja adalah situasi win-win bagi organisasi, studi mengenai turnover memberikan bukti empiris bahwa karyawan berpikir untuk meninggalkan pekerjaan ketika mereka merasa beban kerja yang berlebih, demikian pula lingkungan kerja juga merupakan faktor kunci untuk mempertahankan karyawan peraturan yang dibuat mengenai disiplin kerja yang baik dan transparan akan mengurangi intensi turnover.

\section{DAFTAR RUJUKAN}

Alexander. Jeffrey. A., Richard L., Hyun J.O., Esther Ullman. 2008. "A Causal Model of Voluntary Turnover Among Nursing Personnel in Long-Term Psychiatric Settings". SMITREC. pp. 415-427.

Armstrong, M. 2009. Armstrong's Handbook of Human Resource Management, 
Practice. 11th Edition. Saxon Graphics Ltd. London.

Azwar, S. 2008. Validitas dan Reliabilitas. Sigma Alpha. Yogyakarta.

Berka, Chris, Daniel J. Levendowski., Michelle N. Lumicao., Alan Yau. 2007. "EEG Correlates of Task Engagement and Mental Workload in Vigilance, Learning, and Memory Task". Aviation, Space, and Environmental Medicine. Vol 78 No. 5 bag 2 .

Bukchin, Y., Cohen Yuval. (2013). Minimising Troughput Loss in Assembly Lines due to Absenteeism and Turnover via Work-Sharing. Taylor \& Francis Group. Vol 51, No 20, pp 6140-6151.

Burke, Ronald J; Parbudyal S, Lisa F. 2010. Work Intensity: Potential Antecedents and Consequences. Emerald Group Publishing Limited. Vol. 39 No 3, pp 347-360.

Chong, Vincent K., Gery S.M. 2015. The Impact of the Antecedents and Consequences of Job Burnout on Junior Accountants' Turnover Intentions: A Structural Equation Modelling Approach. AFAANZ. Accounting and Finance 55, pp 105132.

Conklin, Mark H., PharmD, and Shane P. D. 2007. "Job Turnover Intentions Among Pharmacy Faculty". American Journal of Pharmaceutical Education. 71 (4) Article 62.

Dewanti, Rully Nur. 2015. "Pengaruh Gaya Kepemimpinan Transaksional dan Transformasional serta Kepuasan Gaji terhadap Turover Intention di PT. PMMK”, Tesis. Universitas Mercubuana. Jakarta.
Dogbey, Evelyn A. 2008. The Relationships Among Unit Culture, Work Stress, Compassion Fatigue And Sense Of Wellbeing In Operating Room Nurses In Level One Or Two Trauma Centers. ProQuest, pp 11-188

Guglielmi, Dina., Chiara Panara, Silvia Simbula. 2012. "The Determinats of Teachers' Well-Being The Mediating Role of Mental Fatigue". European Journal of Mental Health 7, pp 204220.

Gormley, Denise K., Susan K. 2011. "Predictors of Turnover Intention in Nurse Faculty". SLACK Incorporated, pp 190-196.

Hasibuan, M. 2007. Manajemen Sumber Daya Manusia. Edis revisi. PT. Bumi Aksara. Jakarta.

Hauck. Erica L., Lori Anderson S., Luz Eugenia., Cox Fuenzalida., 2008. "Workload Variability and Social Support: Effects on Stress and Performance". Curr Psychoo. 27:122125.

Hausknecht, John; Julianne M. Rodda, Michael J. Howard. 2009. "Targeted Employee Retention: PerformanceBased and job-Related Differences in Reported Reasons for Staying". Human Resource Management Vol. 48, pp 269-288

https://en.wikipedia.org/wiki/Heteroscedastic ity\#/media/File:Heteroscedasticity.png (diakses tanggal 10 Agustus 2016)

/Homoscedasticity\#/media/File:Hom oscedasticity.png (diakses tanggal 10 Agustus 2016)

Irvianti, Laksmi Sito Dwi; Renno Eka Verina. 2015. Analisis Pengaruh Stres, 
Beban Kerja Dan Lingkungan Kerja Terhhadap Turnover Intention Karyawan Pada PT. XL Axiata Tbk Jakarta. Binus Business Review Vol. 6 No. 1. 117-26

Ivanovic, A., Collin. P. H. 2006. Dictionary of Human Resources and Personnel Management, third edition, A \& C Black Publisher Ltd. London.

Kademi, Mojgan; Eesa Mohammadi, Zohreh Vanaki. 2012. "Nurses' Experiences of Violation of Their Dignity". SAGE. 19(3), pp 328-340.

Kato, Tkao., Cherly Long. 2006. "Executive Turnover and Firm Performance in China". Departmannt of Economics Vol 96, No. 2.

Lavenant, Michael S. 2010. The Art of Employee Discipline: How to Retain Control \& Increase Production, Nonprofit World Vol 28, Number 4 Published by the Society for Nonprofit Organizations, Michigan 48187 734451-3582

Lea, Victoria M; Sarah A. Corlett and Ruth M. Rodgers. 2012. Workload and its Impact on Community Pharmacists' Satisfaction and Stress: a Review of the Literature, International Journal of Pharmacy Practice 20, pp 259-271.

Levin, Scott; France, Daniel J; Hemphill, Robin et.,al. 2006. "Tracking Workload in the Emergency Departemen". ProQuest. 48.3. pp. 526

Makela, Kasper; Mirja Hirvensalo, Peter R. Whipp. 2014. Should I Stay or Shpuld I Go? Physical Education Teachers' Career Intentions. Routledge Taylor \& Francis Group, pp234-244.

Mampane, PM. 2012. The Crisis of Teacher Turnover. A Threat To Public Service
Stability, GCBF. Vol. 7 No 1, pp. 293301

Mangkunegara, A.A.A.P. 2013. Manajemen Sumber Daya Manusia Perusahaan, PT. Remaja Rosdakarya, Bandung.

Mansoer, Muhammad Ikbal. 2014. "Pengaruh Disiplin kerja dan Sistem Kompensasi terhadap Kinerja Pegawai Negri Sipil di Dinas Pengelolaan Keuangan dan Aset Daerah Kota Ternate", Tesis Program Studi Magister Manajemen. Program Pascasarjana Universitas Mercubuana.

Mathis, Robert L., Jackson John H. 2010. Human Resource Managemen Thirteenth Edition, South-Western Cengage Learning USA.

Mello, Jeffrey A. 2011. Strategic Human Resource Management 3rd Edition, Cengage Learning, South-Western, USA.

Mosadeghrad, Ali. M. 2013. "Occupational Stress and Trunover Intention: Implications for Nursing Management". International Journal of Health Policy and Managememnt. I(2). pp 169-176.

Nandini, Nurhasmadia. Thinni Nurul R. 2013. Penyebab Turnover Intention Pada Pegawai Instalasi Gizi Rumah Sakit PHC Surabaya. Jurnal Administrasi Kesehatan Indonesia Vol. 1 No. 3. 272-279.

Neumann, W. Patrick, Jan Dull. 2010. Human factors: spanning the gap between OM and HRM. Emerald. Vol. 30 No. 9. pp 923-950.

Pierre, Sebastien Fournier. et al. 2011. Exploratory Study to Identify Workload Factors that Have an Impact on Health and Safety. A Case Study in 
Service Sector. Studies and Research Projects, Irsst, Québec.

Qureshi, Muhammad Imran; Mehwish Iftikhar, Syed Gohar Abbas, Umar Hassan, Khalid Khan and Khalid Zaman. 2013. "Relationship Between Job Stress, Workload, Environment and Employees Turnover Intentions: What We Know, What Shoul We Know". World Applied Sciences Journal 23 (6) pp. 764-770.

Rambur, Betty; Palumbo, Mary Val. 2008. "A Cross-Disciplinary Statewide Healthcare Workforce Analysis". Journal of Allied Health. 37.2. pp. 105.

Sadili, Samsudin, Wijaya, E. 2006. Manajemen Sumber Daya Manusia. Pustaka Setia, Bandung.

Singarimbun, Masri, Sofian Efendi. 2006. Metode Penelitian Survai, Cetakan ke 18 (Revisi). LP3ES, Jakarta.

Singh, Kultar. 2007. Quantitative Social Research Methods. Sage Publications. India.

Silaen, Sofar dan Widiyono. 2013. Metodologi Penelitian Sosial Untuk Penulisan Skripsi dan Tesis. In Media, Jakarta.

Sugiyono, 2010. Metode Penelitian Kuantitatif, Kualitatif, dan $R \& D$, Alfabeta, Bandung.

Sulistiyani, A. T., dan Rosida. 2009. Manajemen Sumber Daya Manusia "Konsep, Teori dan Pengembangan dalam Konteks Organisasi Publik", Edisi Kedua, Graha Ilmu, Yogyakarta.

Sujarweni, V. Wiratna. 2015. SPSS untuk Penelitian. Pustaka Baru Press. Yogyakarta.
Sunyoto, D. 2011. Pratis SPSS Untuk Kasus. Nuha Medika, Yogyakarta.

Supranto, dan Limakrisna Nandan. 2013. Petunjuk Praktis Penelitian Ilmiah untuk Meyusun Skripsi, Tesis, dan Disertasi, Edisi 3. Penerbit Mitra Wacana Media: Jakarta.

Thibodeaux, Amy K., Myron B. Labat, David E. Lee, Cherie A. Labat, 2015. The Effects Of Leadership And HighStakes Testing On Teacher Retention. Academy of Educational Leadership Journal Volume 19, Number 1, pp 227249.

Umar, Husein. 2013. Desain Penelitian MSDM dan Perilaku Karyawan: Paradigma Positivistik dan Berbasis Pemecahan Masalah. Edisi 1-4. Rajawali Pers. Jakarta

Universitas Mercubuana. 2016. Buku Bimbingan Penyusunan Tesis Edisi 10 Program Magister Manajemen. Universitas Mercubuana. Jakarta.

Wastlund Erk. 2007. Experimental Studies of Human-Computer Innteraction: Working memory and mental workload in complex cognition". Departement of Psychology. Gohenburg.

Wisantyo, Nurmalitasari Indah. 2015. Pengaruh Stres Kerja, Disiplin Kerja dan Kepuasan Kerja Terhadap Intensi Turnover (Studi pada Lembaga Pengelola Dana Bergulir Koperasi dan Usaha Mikro, kecil dan menengah). Jurnal MIX, Volume V, No. 1, pp. 5469. 